\title{
Total Column Ozone Variability and Trends over Kenya using Combined Multiple Satellite-Based Instruments
}

\author{
Carolyne M. M. Songa ${ }^{1,2}$, Jared H. O. Ndeda ${ }^{2} \&$ Gilbert Ouma $^{3}$ \\ ${ }^{1}$ Natural Science Department (Physics), Faculty of Science, The Catholic University of Eastern Africa, Nairobi, \\ Kenya \\ ${ }^{2}$ Physics Department, Jomo Kenyatta University of Agriculture and Technology, Nairobi, Kenya \\ ${ }^{3}$ Meteorological Department, University of Nairobi, Kenya \\ Correspondence: Carolyne M. M. Songa, The Catholic University of Eastern Africa, P.O. Box 62157 - 00200 , \\ Nairobi, Kenya. Tel: 254-724-508-575. E-mail: cmutambi@cuea.edu
}

Received: July 13, 2014 Accepted: August 9, 2015 Online Published: September 7, 2015

doi:10.5539/apr.v7n5p87 URL: http://dx.doi.org/10.5539/apr.v7n5p87

\begin{abstract}
We investigate the trends and variability in Total Column Ozone (TCO) over three Kenyan cities; Nairobi (1.17 $\left.\mathrm{S} ; 36.46^{\circ} \mathrm{E}\right)$, Kisumu $\left(0.03^{\circ} \mathrm{S} ; 34.45^{\circ} \mathrm{E}\right)$ and Mombasa $\left(4.02^{\circ} \mathrm{S} ; 39.43^{\circ} \mathrm{E}\right)$ from 1985 - 2011 using TCO data from combined multiple satellite-based instruments to create a single near-global daily time series. Monthly, annual and seasonal means are calculated based on the measures of TCO daily values. A visual depiction of the trends and variability in TCO is provided by means of the time series. Annual, monthly and seasonal trends in TCO are calculated from straight line fits whereby the net ozone changes over the 27 years analysis can be determined. Quantification of the observed changes in TCO percentage variability is also calculated. Annual means and standard deviations of TCO estimated at Nairobi, Kisumu and Mombasa are 254.75 \pm 5.17 DU, 253.92 \pm 5.20 DU and $257.07 \pm 4.70$ DU respectively. Over the period $1985-2011$ a decreasing trend of $0.031 \%$ year $^{-1}$ is observed at Nairobi, $0.026 \%$ year $^{-1}$ at Kisumu and $0.031 \%$ year $^{1}$ at Mombasa equating to losses of 2.158 DU at Nairobi, 1.759 DU at Kisumu and 2.164 at Mombasa. TCO annual variability ranges between $1 \%$ and $6 \%$, while the seasonal variability ranges between $2 \%$ and $4 \%$. The slope of the line of fit exhibit a negative sign showing a statistically decreasing trend over time in all the three locations under study, hence, temporal variability of TCO in all the three cities is declining.
\end{abstract}

Keywords: combined multiple satellite-based instruments, Dobson Units, time series, Total Column Ozone, trend, variability

\section{Introduction}

The atmosphere, which consists of the lower, middle and upper atmosphere levels, is the transition zone between earth and space made up of a mixture of gases. These gases are exposed to the sun's electromagnetic spectrum. In the middle atmosphere, ozone plays a major role in both radiation and chemistry. The Global Climate Observing System (GCOS), in their report (GCOS, 2010), identified Total Column Ozone (TCO) to be among the fifty Essential Climate Variables (ECVs). Both stratospheric depletion and tropospheric excess of ozone are harmful to the biosphere. This calls for the monitoring of ozone concentration variations and trends in both the stratosphere and troposphere.

TCO is a measure of the vertically integrated ozone molecules in the atmosphere's column above a specific location and hence relates directly to the amount of UV radiation reaching earth's surface (Obiekezie, 2009). The global distribution of TCO is well known (Stanford, Ziemke, McPeters, Krueger, \& Bhartia, 1995; Plumb, 2002; Zahid \& Rasul, 2010). At equatorial latitudes, a minimum of around 260 DU (Dobson Units; defined as $0.01 \mathrm{~mm}$ total thickness of the ozone layer at standard temperature and pressure, that is, $0^{\circ}$ Celsius and one atmosphere pressure; 1 DU contains $2.69 \times 10^{16}$ molecules $\mathrm{cm}^{-2}$, increasing to between $300-350 \mathrm{DU}$ at mid latitudes and increasing further towards the North and South poles reaching a maximum value of approximately $450-500 \mathrm{DU}$ at sub-polar latitudes.

Stratospheric ozone is produced by the ultraviolet radiation. The amount of ozone in any region depends on the balance between ozone production and loss processes and the transport of ozone by atmospheric dynamics (Haynes, 
2005; Garny, Grewe, Dameris, Bodeker, \& Stenke, 2011). There is more ultraviolet radiation over the equator, as compared to high latitudes, hence ozone production. It is therefore expected that the highest concentration of ozone levels must be found over the tropics and the lower levels over the Polar Regions, but this is not the case, the observed behavior is quite different. The high-latitude maximum ozone is due to ozone transport from the equator, which is source to higher latitudes (Whitten \& Prasad, 1985). TCO amounts near the equator are rather low, that is, less than the typical global average of $\cong 300 \mathrm{DU}$. These low TCO amounts in the tropics combined with the direct overhead sun, create the very high amounts of UV levels (Bais \& Lubin, 2006). Chapman (1930) proposed the fundamental ozone formation and destruction chemical reactions which include the photolysis of molecular oxygen by solar ultraviolet (UV) radiation $(\lambda<242 \mathrm{~nm})$ given by reaction 1 below. The rapid reaction of oxygen atoms $(\mathrm{O})$ from reaction 1 with $\mathrm{O}_{2}$ in the presence of a third molecule $\mathrm{M}$, usually $\mathrm{O}_{2}$ or $\mathrm{N}_{2}$, form ozone (reaction 2). Photolysis of ozone molecules from reaction 2 by radiation at wavelengths less than $320 \mathrm{~nm}$ produces $\mathrm{O}$ and $\mathrm{O}_{2}$ through reaction 3 below. $\mathrm{O}_{3}$ can also react very fast with atomic oxygen and convert back to $\mathrm{O}_{2}$ molecules via reaction 4 .

$$
\begin{gathered}
\mathrm{O}_{2}+h v \rightarrow 2 O \\
O+\mathrm{O}_{2}+M \rightarrow \mathrm{O}_{3}+M \\
\mathrm{O}_{3}+h v \rightarrow O+\mathrm{O}_{2} \\
\mathrm{O}+\mathrm{O}_{3} \rightarrow 2 \mathrm{O}_{2}
\end{gathered}
$$

Haigh (1994) and Dessler (2000) observed that solar enhanced ozone variations are possible due to solar ultraviolet (UV) irradiance changes. The UV irradiance is capable of modifying the ozone production rates through molecular oxygen photolysis basically at low latitudes in the middle to the upper stratosphere. According to Randall et al., (2007), solar enhanced ozone variations are possible due changes in high energetic charged particles precipitation rate indirectly modifying the concentration of ozone by catalytically changing the trace species abundance which destroy ozone fundamentally at the polar latitudes. Transport enhanced ((Hood \& Soukharev, 2003; Rind et al., 2004; Shindell et al., 2006; Gray, Rumbold, \& Shine, 2009; Gray, 2010) ozone changes occur because of BrewerDobson circulation (Andrews, 2000), quasi-biennial oscillation (Baldwin et al., 2001) and the El-Nino Southern Oscillation (Akinyemi, 2007), which indirectly affect circulation.

The use of satellite measurements to investigate stratospheric ozone variations and trends, as well as their seasonal, longitudinal and latitudinal structure has contributed immensely to a global view of the climatology of and variability in stratospheric ozone (Oyekola, 2011). The purpose of this study is to quantify trends and variability in TCO over three Kenyan cities using data from combined multiple satellite-based instruments to create a single near-global daily time series of TCO fields.

\section{Materials and Methods}

\subsection{Total Column Ozone Dataset}

A near-global TCO database at $1.25^{\circ}$ longitude by $1^{\circ}$ latitude, combining measurements from multiple satellitebased instruments (Bodeker, Hassler, Young, \& Portmann, 2013) has been used to interpolate data to the three locations of interest in Kenya. The Bodeker scientific database extends from $1^{\text {st }}$ November 1978 to 2013 and can be obtained from data site: http://www.bodekerscientific.com/data/total-column-ozone. Comparisons against TCO measurements from the ground-based Dobson and Brewer spectrophotometer network are used to remove offsets and drifts between a subset of the satellite-based instruments. The corrected subset is then used as a basis for homogenizing the remaining data sets.

The construction of this database improves on earlier versions of the database by including a wider range of satellite-based instruments, using updated versions of the source satellite data, extending the period covered, using improved statistical methods to model the difference fields when homogenizing the data sets, and, perhaps most importantly, robustly tracking uncertainties from the source data sets through to the final climate data record which therefore now comes with associated uncertainty fields (Bodeker et al., 'in preparation'). The combined TCO database is validated against other global TCO datasets as detailed in Bodeker et al. (in preparation').

\subsection{Study Area Descriptions}

Kenya is located in the Eastern part of Africa $\left(5^{\circ} \mathrm{N}, 4.40^{\circ} \mathrm{S}\right.$ and $\left.33.53^{\circ} \mathrm{E}, 41.56^{\circ} \mathrm{E}\right)$ and has a total area of 582,646 $\mathrm{km}^{2}$. Annual, monthly and seasonal variations in TCO, as well as trends and variability are examined at three main Kenyan cities namely Nairobi, Kisumu and Mombasa. Table 1 shows the codes, positions and elevations of the three cities. TCO trends and variability has not been carried out in major towns and cities. 
Table 1. Names, codes, position and elevation of the three Kenyan cities

\begin{tabular}{lcccc}
\hline Station & Code & Latitude $\left({ }^{\circ} \mathrm{S}\right)$ & Longitude $\left({ }^{\circ} \mathrm{E}\right)$ & Altitude (m, asl) \\
\hline Nairobi & $\mathrm{nrb}$ & 1.17 & 36.46 & 1661 \\
Kisumu & $\mathrm{ksm}$ & 0.03 & 34.45 & 1131 \\
Mombasa & $\mathrm{msa}$ & 4.02 & 39.43 & 17 \\
\hline
\end{tabular}

as $\mathrm{l}=\mathrm{above}$ sea level.

Nairobi is centrally located in the country and covers an area of $684 \mathrm{~km}^{2}$. It is the country's capital and largest city and holds a population of 3.1 million people (Kenya National Bureau of Statistics [KNBS], 2010). Mombasa is Kenya's second largest city, located on the South Eastern coast of the country, along the Indian Ocean. The city has an area of $295 \mathrm{~km}^{2}$ and a population of 939370 people (KNBS, 2010). Kisumu is the third largest city in Kenya. It is located in Western Kenya and covers an area of approximately $417 \mathrm{~km}^{2}$, with a population of 968909 people (KNBS, 2010).

\subsection{Methodology}

Monthly, annual (yearly) and seasonal means are calculated based on the daily TCO values assuming that they are representatives of daily means. The monthly average is then used to determine the monthly variability. Annual averages are calculated by averaging the monthly means. A visual depiction of the trends and variability in TCO is provided by means of the time series at the three cities (Figure 1 - discussed further below). To illustrate larger timescale trends, the seasonal variations are minimized by smoothing the time series with 13 month running mean.

Seasonal variability in TCO is calculated by using the monthly average for December, January and February (DJF), March, April and May (MAM), June, July and August (JJA), and September, October and November (SON).

Annual, monthly and seasonal trends in TCO at the three Kenyan cities were calculated from straight line fits. Net ozone changes over the 27 year analysis period are determined by multiplying the slope in (DU/year) by 27 . Percentage variability in TCO is also calculated.

\section{Results and Discussions}

\subsection{Trend Analysis}

The trends derived from linear fits to the monthly mean TCO time series from 1985 - 2011 are shown in Figures $1(\mathrm{a})-(\mathrm{c})$.

One gross feature is the apparent decrease in TCO with time. The linear fits show that the trend in TCO is not identical at all the locations. The linear trends shown in Figures 1(a) - (c) suggest decreases of 2.158 DU at Nairobi, 1.759 DU at Kisumu and 2.164 DU at Mombasa over the 27 year period of analysis. These trends are consistent with trends expected in the equatorial region where trends are expected to be zero or a minimum compared with TCO trends in the middle and higher latitudes. Hence, there is a decreasing trend of TCO and this loss in TCO gives a clue that, during the study period, ozone layer thickness is reducing.

Stratospheric structure is divided into distinct regions, that is, the upper, middle and lower stratosphere, all of which have no interaction with the troposphere via isentropic transport and then the lower-most stratosphere which does interact with the upper troposphere via isentropic transport (Holton, Haynes, McIntyre, Douglas, Rood \& Pfister, 1995). In the stratosphere, the tropics stretch from $15^{\circ} \mathrm{S}$ to $15^{\circ} \mathrm{N}$. This is the primary photochemical source region of ozone production due to high levels of radiation at wavelengths less than $242 \mathrm{~nm}$ (reaction 1 above). The middle latitudes are characterized by the turbulent mixing of air masses. The lower-most stratosphere contains a mixture of both the tropospheric and stratospheric air.

An air parcel movement can be in three dimensions namely in the zonal or east - west direction which is caused by meridional temperature gradients (Holton, 2004), vertically, which is weaker than the zonal and meridional circulations in terms of mass flux and is generated by stratospheric wave forcing (Dessler, 2000), and meridionally (north-south) direction (Brasseur \& Solomon, 2005).

The negative trend could be attributed to atmospheric dynamics specifically the meridional circulation, which is the main source of transport at latitudes near the equator. This meridional circulations generally referred to as the Brewer-Dobson circulation is driven by breaking and dissipating Rossby waves and gravity waves which dissipate their momentum in the extra tropics creating a "suction pump" which causes large scale upward transfer of air masses from the tropics into the mid and higher latitude regions (Holton et al., 1995). 

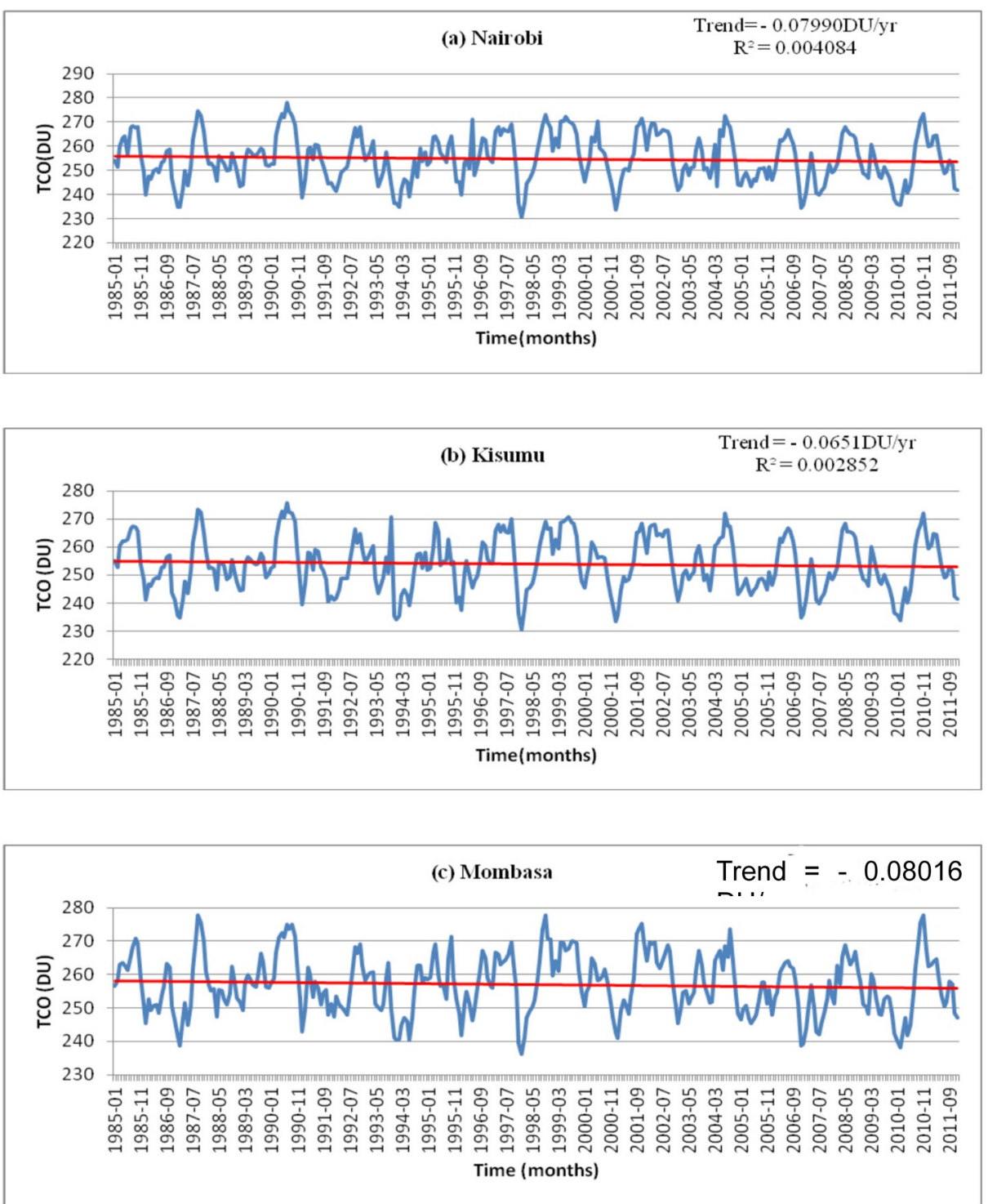

Figure 1. Monthly mean TCO time series from 1985 - 2011 together with their linear fits for (a) Nairobi, (b) Kisumu and (c) Mombasa

Table 2. Descriptive statistics of TCO for Kenyan cities during the study period from $1985-2011$

\begin{tabular}{lccc}
\hline & \multicolumn{3}{c}{ TCO (DU) } \\
\cline { 2 - 4 } & Nairobi & Kisumu & Mombasa \\
\hline Mean & 254.75 & 253.92 & 257.07 \\
SD & 9.76 & 9.54 & 8.84 \\
Median & 253.72 & 253.2 & 256.95 \\
CV & $3.83 \%$ & $3.76 \%$ & $3.44 \%$ \\
Max & 277.93 & 275.85 & 277.86 \\
Min & 230.55 & 230.47 & 236.09 \\
Range & 47.39 & 45.38 & 41.77 \\
Skewness & 0.019 & 0.023 & 0.063 \\
Kurtosis & -0.711 & -0.738 & -0.592 \\
\hline
\end{tabular}

$\mathrm{SD}=$ Standard Deviation $\mathrm{CV}=$ Coefficient of Variation. 
Table 2 shows the various statistical attributes of TCO at Nairobi, Kisumu and Mombasa during the study period. Mombasa registered a maximum monthly average TCO of 277.86 DU in October 1998 while Nairobi achieved a maximum of 277.93 DU in July 1990 and Kisumu a maximum of 275.85 DU in July 1990. Monthly mean minima of 230.55 DU at Nairobi, 230.47 DU at Kisumu and 236.09 DU at Mombasa were all observed in January 1988.

The temporal distribution of TCO in the three cities is approximately symmetrical (skewness $\approx 0$ and hence mean $\approx$ median) and a value less than the kurtosis threshold $(<3)$ is observed. Among the locations, Mombasa had the lowest coefficient of variation of $3 \%$ compared to Nairobi and Kisumu, both had $4 \%$.

Another persistent feature, as observed in Figure 1, is the presence of strong seasonal cycles i.e. high frequency variations from the data and also reduction of seasonal amplitude with time. The strong seasonal cycles resulted in low coefficient of determination, $\left(\mathrm{r}^{2}\right)$, that is, 0.0041 at Nairobi, 0.0029 at Kisumu and 0.0050 at Mombasa. A low value of $r^{2}$ indicates that the regression line can account for only a small percentage of the variations in total column ozone.

Figure 2 shows line plots of the monthly mean TCO for the three cities for the same time period but the seasonal variation (high frequency variations) has been reduced using the 13 months running mean. Using the linear fit, the same decreasing trend (dashed lines) observed in Figure 1 is observed. A polynomial fit is also included which indicates that most of the decrease in TCO that is evident in Figure 1 took place between 1999 and 2010.

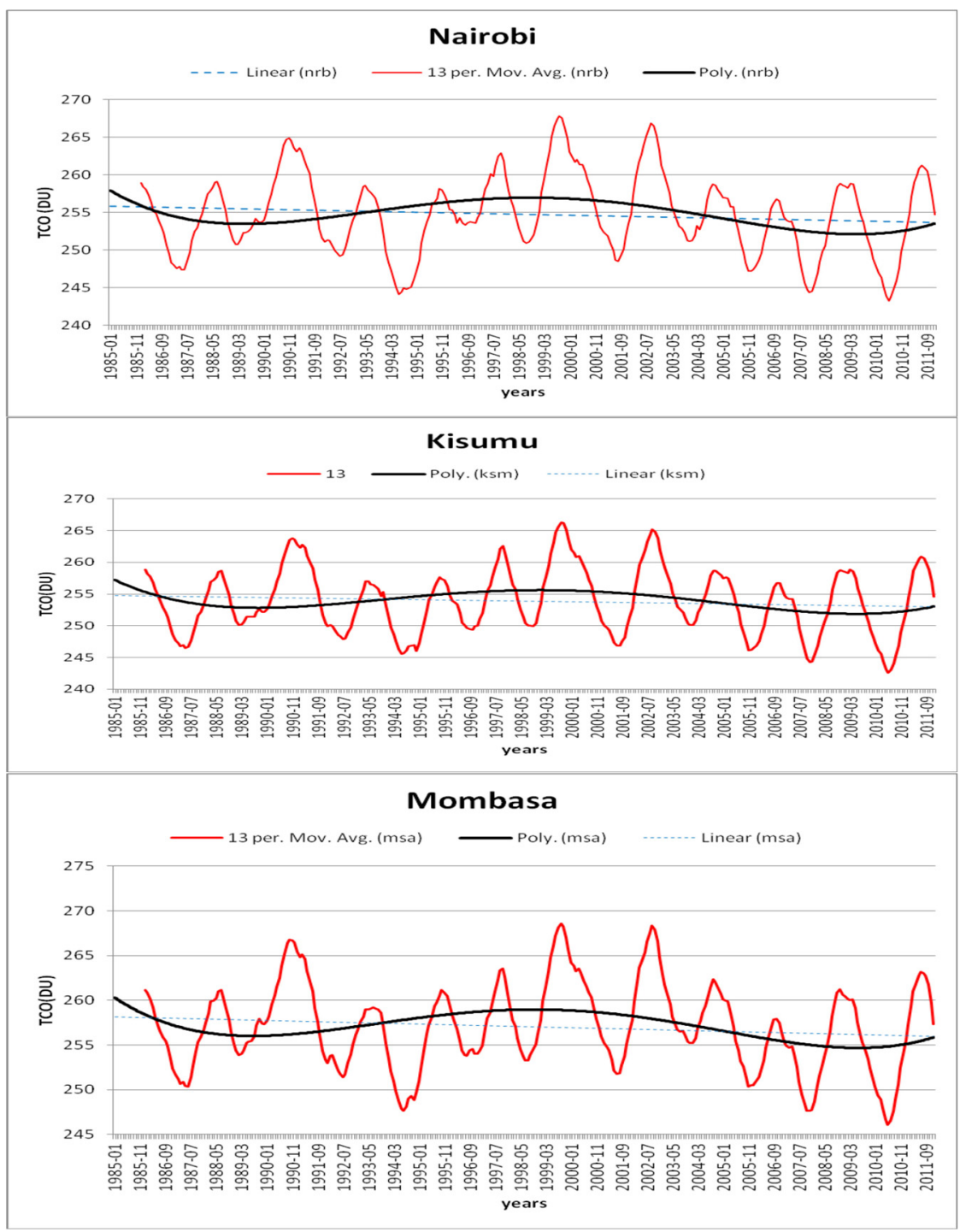

Figure 2. Line plots of TCO at Nairobi, Kisumu and Mombasa for the $1985-2011$ period showing the thirteen running mean (red) and linear fit (dashed line) and polynomial fit (black) 


\subsection{Annual Analysis}

The annual analysis of TCO data has been done by generating time series plots for the period $1985-2011$. The line plots in Figure 3 shows considerable variation in TCO amounts over the years. Some years are low, some high and many in between the minimum value of TCO (260 DU) found at the equatorial latitudes.

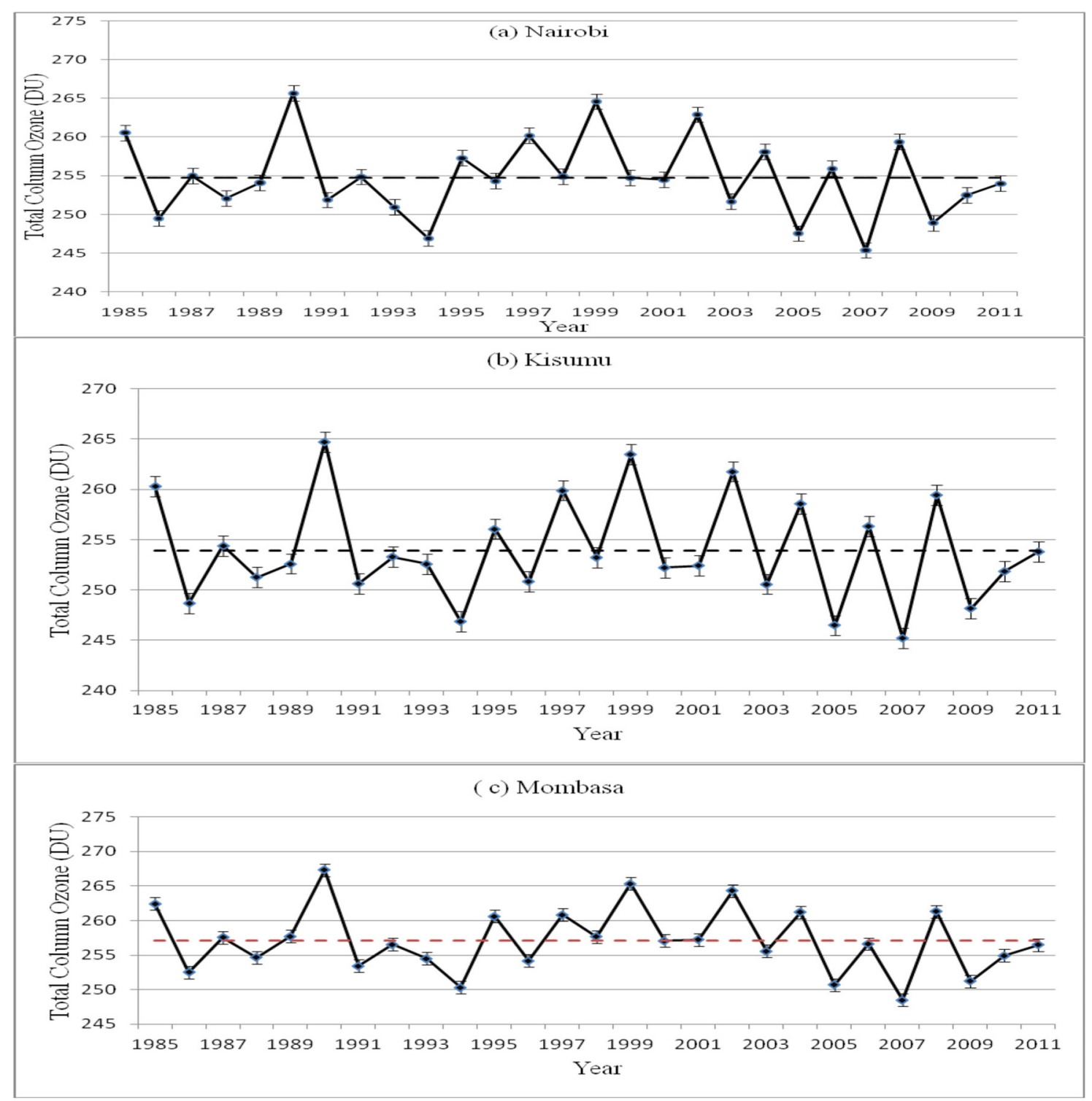

Figure 3. The time series of the TCO with normalized standard deviations for each year observed in (a) Nairobi, (b) Kisumu and (c) Mombasa over 27 years period

Annual means and standard deviations of TCO estimated at Nairobi, Kisumu and Mombasa are $254.75 \pm 5.17$ DU, $253.92 \pm 5.20 \mathrm{DU}$ and $257.07 \pm 4.70 \mathrm{DU}$ respectively. The dashed line in Figure 3 indicates the annual mean TCO for each location.

Annual mean TCO at Mombasa averaged higher than that at Kisumu and Nairobi. As we go from Kisumu to Mombasa, the TCO level is increased by 3.15 DU.

The maximum observed annual mean TCO over the Kenyan locations occurred at Mombasa (267.33 DU) in 1990. At Nairobi and Kisumu, a maximum value of 265.68 DU and 264.72 DU respectively and both in the year 1990 . For the years analyzed, the minimum annual TCO values of 245.37 DU and 245.19 DU were found in 2007 for both Nairobi and Kisumu. At Mombasa, a minimum annual TCO value of 248.51 DU was observed in the year 
2007. Figure 4 shows that the value of TCO in all the three stations is below the recommended amount of (260 DU as in the tropics) in many of the years and that is also quite below the standard value of $300 \mathrm{DU}$ in all the stations. Hence the maximum and minimum observed annual TCO occurred respectively in the year $1990(267.33$ DU) and in 2007 (245.19 DU). Throughout the study period, Mombasa recorded the highest value of TCO, followed by Nairobi while Kisumu recorded the lowest value of the TCO.

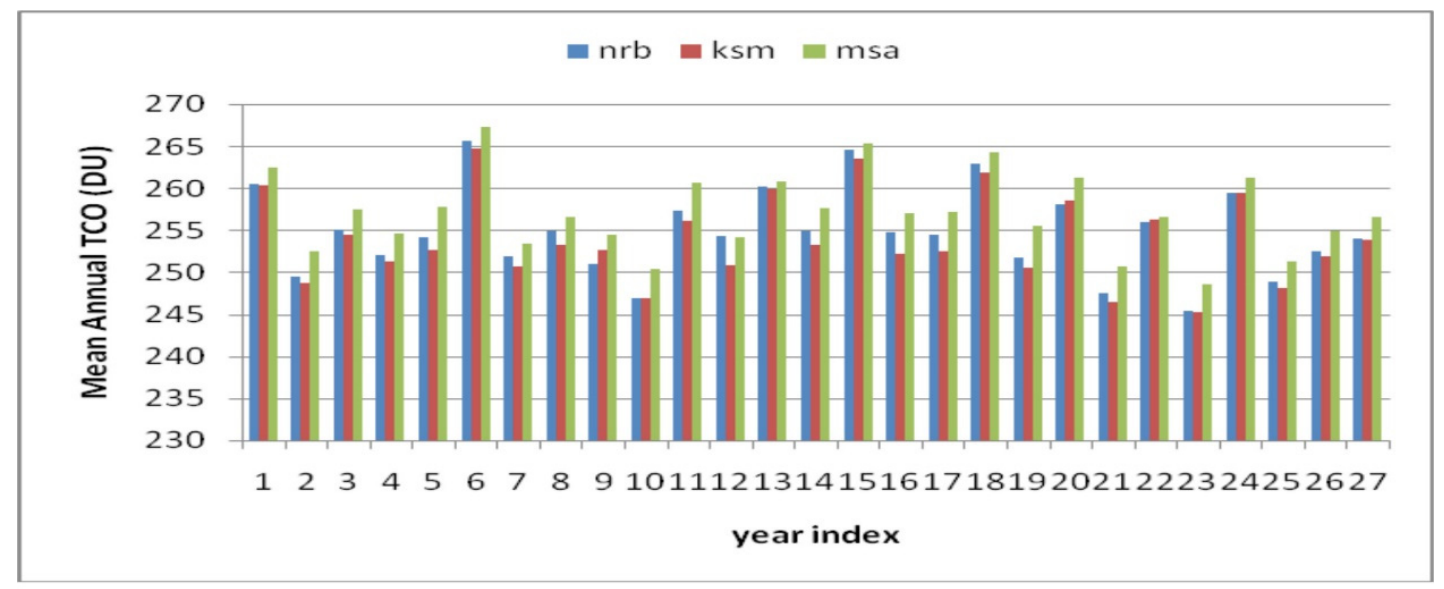

Figure 4. A comparison of TCO values at Nairobi, Kisumu and Mombasa over a period 1985-2011 with year index One $=1985$ and year index $27=2011$

\subsection{Annual Variability}

To quantify the observed changes in annual TCO, the percentage ozone variability is determined. Percentage annual TCO variability is determined in terms of ratio between the annual standard deviation and respective annual mean variation as displayed in Figure 5.

The yearly TCO percentage variability ranges between $1 \%$ to $6 \%$ with highest $(5.76 \%)$ observed at Mombasa in 2010. Nairobi and Kisumu recorded 5.58\% and 5.45\% respectively in 1987 . The lowest observed percentage TCO variability is at Kisumu (0.99\%) in 2005 as compared to Nairobi (1.16\%) and Mombasa (1.45\%).

The Quasi-biennial Oscillation (QBO) is a large-scale atmospheric phenomenon that causes year to year variability in the TCO distribution (Reid, 1994). The QBO refers to reversal in the direction of the zonal winds in the tropical stratosphere which at altitudes between $15 \mathrm{~km}$ and $30 \mathrm{~km}$ occurs on a timescale of 26 to 28 months. It is caused by the internal dynamics of tropical waves.

The QBO also drives changes in temperature which can then change reaction rates and thus ozone amounts. The QBO also modifies the strength of the Brewer-Dobson circulation. When the QBO is in its easterly phase, planetary waves are refracted poleward creating a more disturbed and hence warmer polar vortex. The QBO also drives changes in temperature which can then change reaction rates and thus ozone amounts The QBO also modifies the strength of the Brewer-Dobson circulation. When the QBO is in its easterly phase, planetary waves are refracted poleward creating a more disturbed and hence warmer polar vortex.

A positive temperature gradient from pole to equator (cold to warm) causes westerly winds that strengthen with height, and vice versa. Atmospheric temperature can affect ozone in two ways. First, temperatures modulated photochemical reaction rates as detailed in reactions (1) to (4). Secondly, temperatures directly influence the circulation by amending the heating and cooling rates.

The predominant winds over the Nairobi and Kisumu cities are easterlies while south easterlies over Mombasa (Ongoma, Muthama \& Gitau (2013). The easterly winds are generally stronger than the westerly winds and they persist for longer at upper levels (approx. $30 \mathrm{~km}$ altitude) and have maximum speeds centered over the equator near $26 \mathrm{~km}$ altitude. Westerly winds descend faster than the easterlies and persists for longer at lower levels than the easterly winds. Below $30 \mathrm{~km}$ altitude in the tropical regions ozone is primarily under dynamical control and is therefore affected by the QBO-induced circulation, as well as the Brewer- Dobson circulation which has its upwards branch over the equatorial region. Above $30 \mathrm{~km}$ altitude, ozone becomes increasingly under photochemical control and responds to the QBO-induced temperature changes rather than transport effects. 


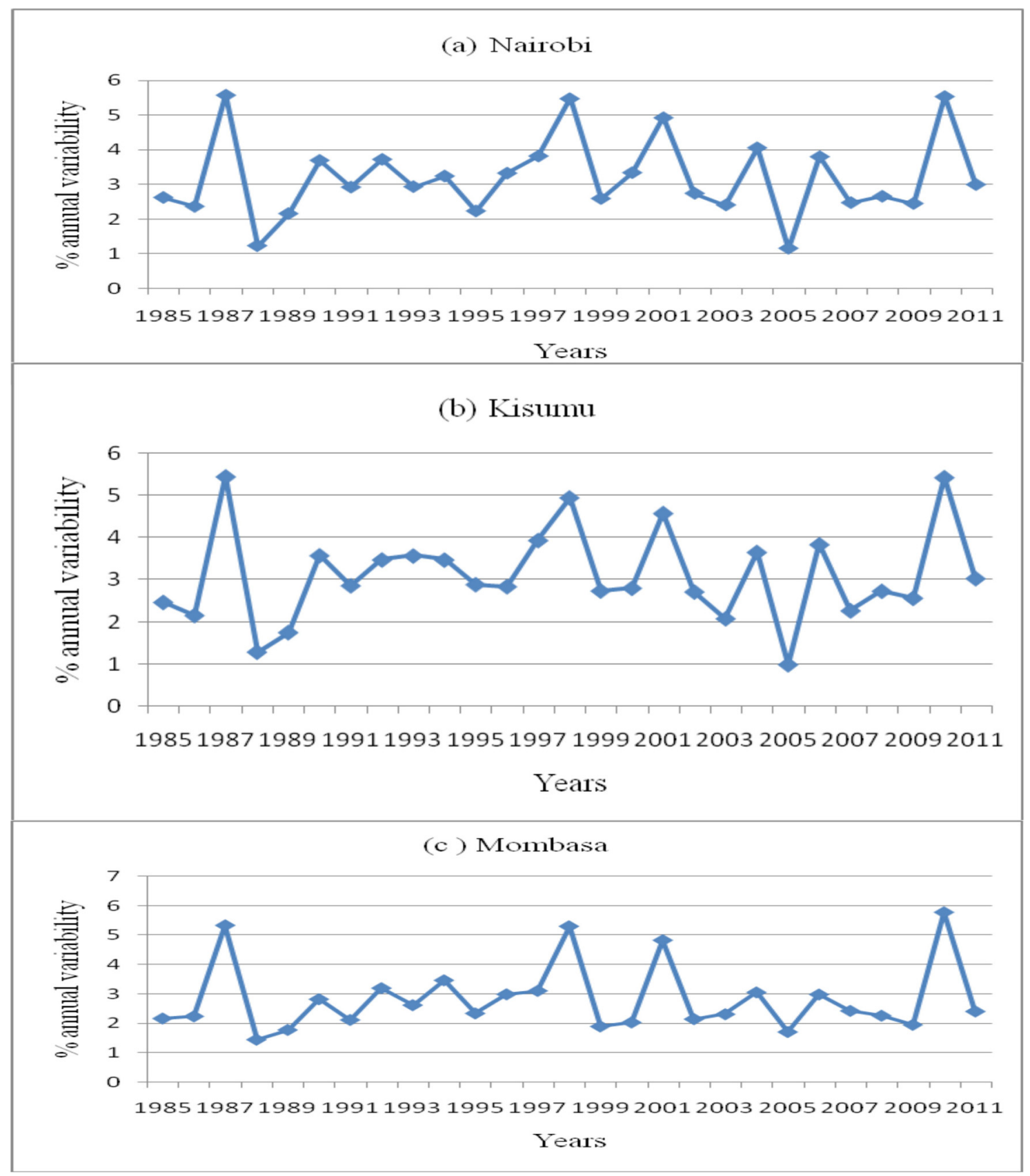

Figure 5. Annual mean percentage variation of TCO at (a) Nairobi, (b) Kisumu and (c) Mombasa

\subsection{Monthly Analysis}

The monthly analysis of TCO for all considered cities shows a large variation of TCO throughout the months in the 27 years. Figure 6 illustrates the average monthly values of TCO of each month of the year for the three Kenyan cities and shows also the general picture of how TCO varied from January to December for all the years. The temporal patterns of monthly mean TCO for Nairobi, Kisumu and Mombasa showed a similar curve across the months with two maximum peaks. There was a major maximum peak in the month of September and a minor maximum peak in the month of April for all the cities.

The major maximum peak is in the August - October season, which is just before the start of the short rains while the minor maximum peak is during the long rains in March - May. Hence, maximum values of TCO coincide with rainfall. The same results and pattern were observed by Thiong'o (2014), in his report during the ozone research managers. 


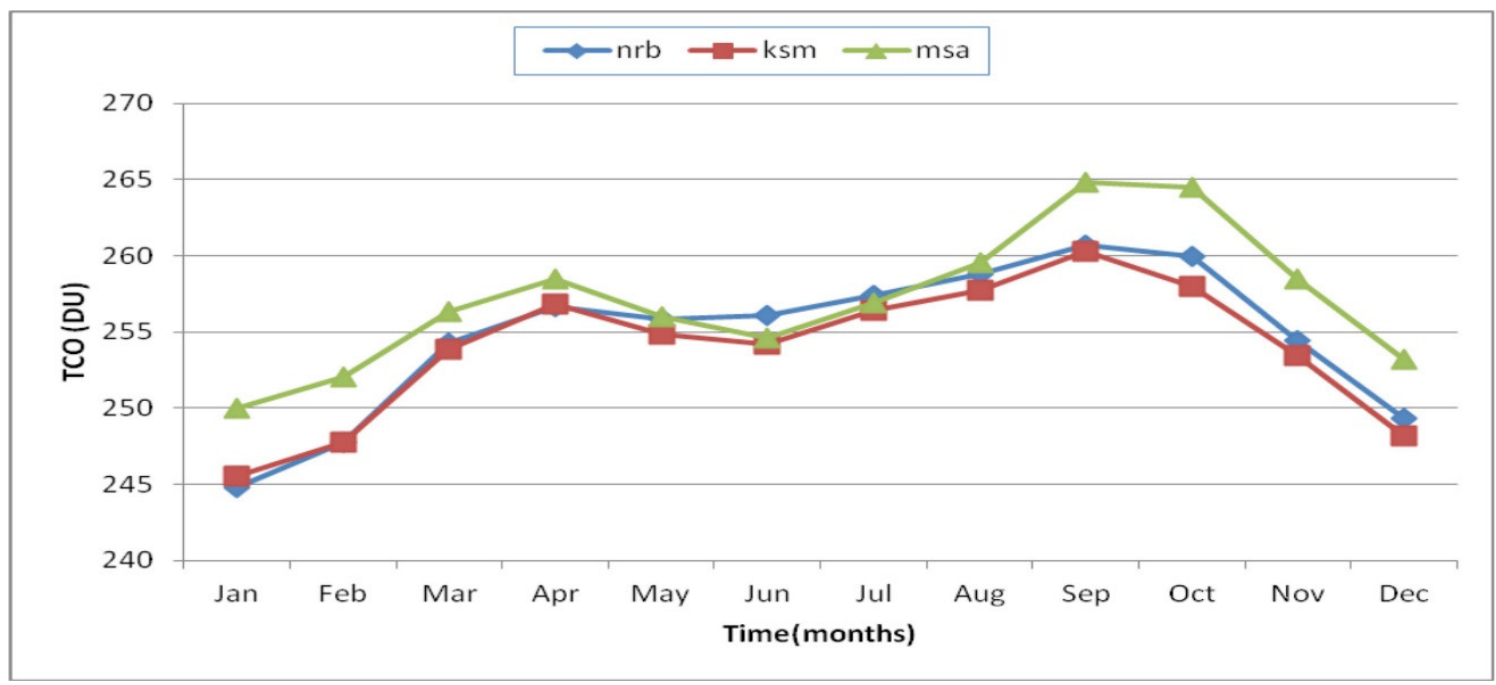

Figure 6. The seasonal variation of Total Column Ozone for all the years

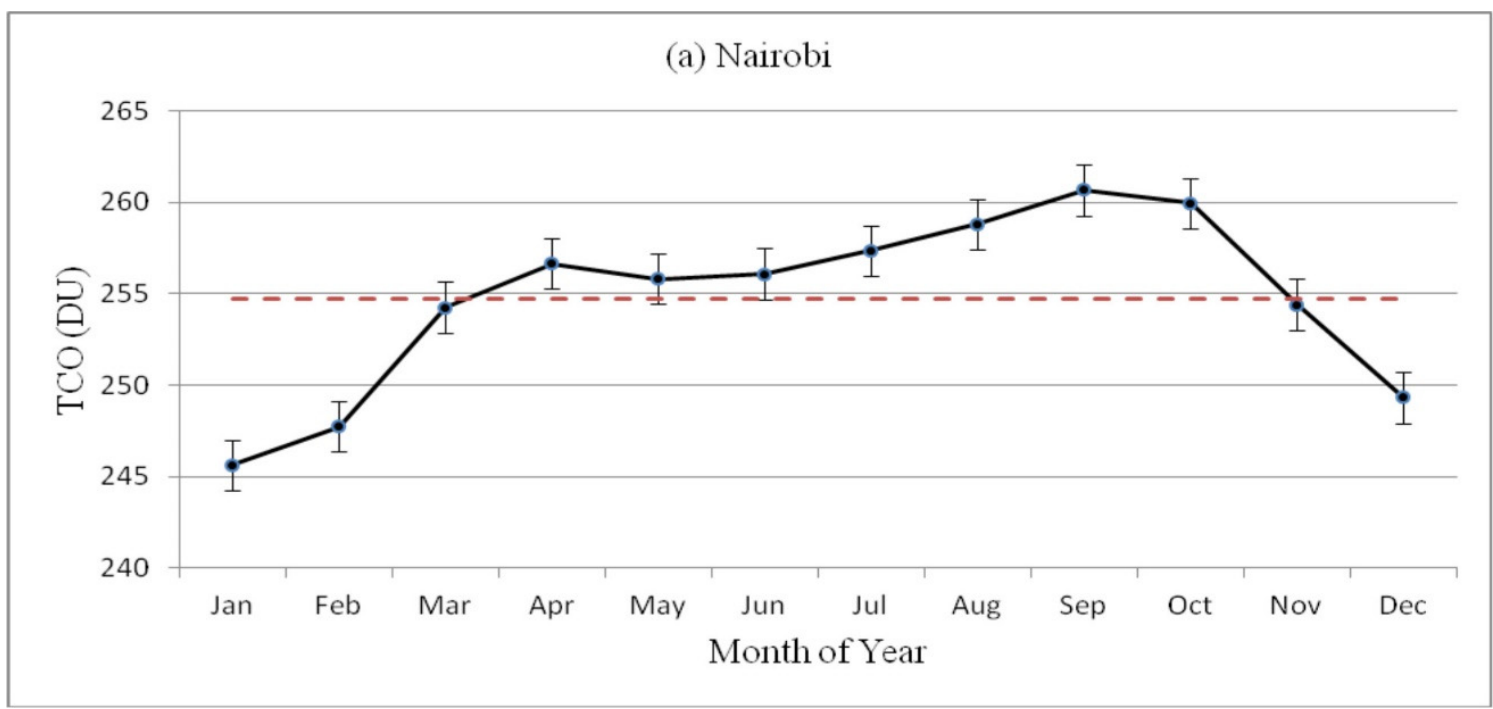

Figure 7(a). Plots of mean seasonal TCO variability measured at Nairobi

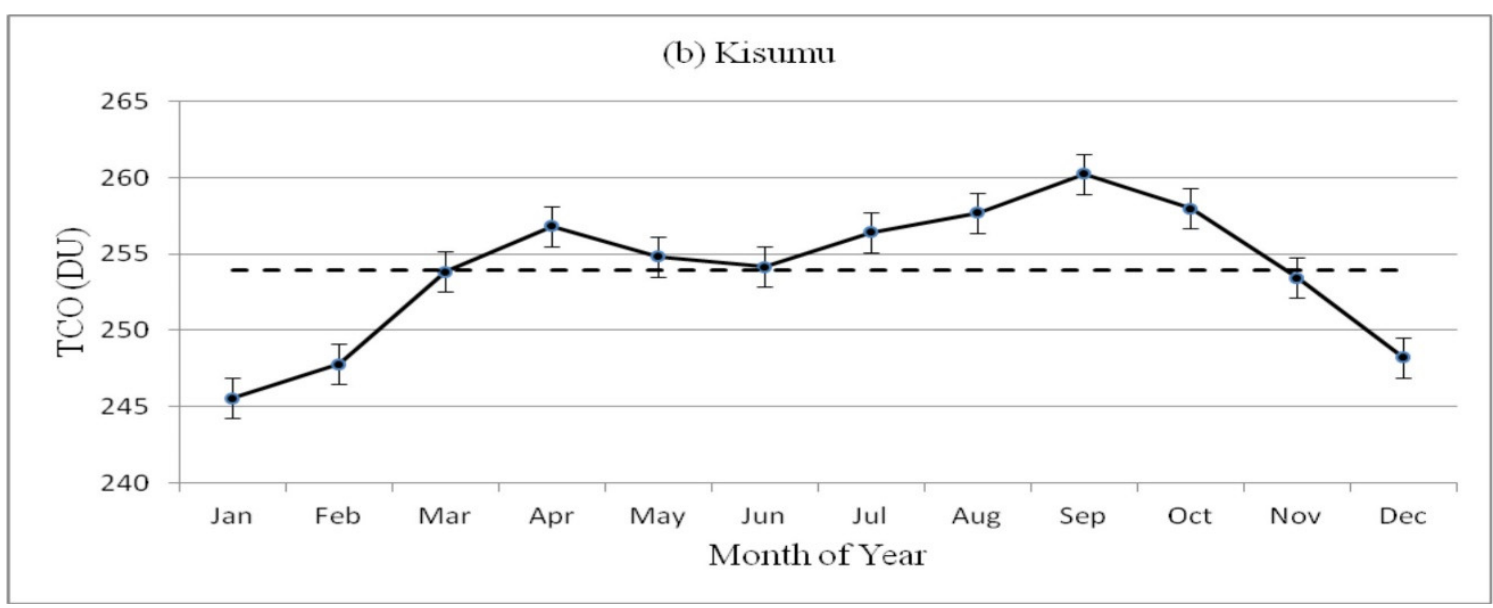

Figure 7(b). Plots of mean seasonal TCO variability measured at Kisumu 


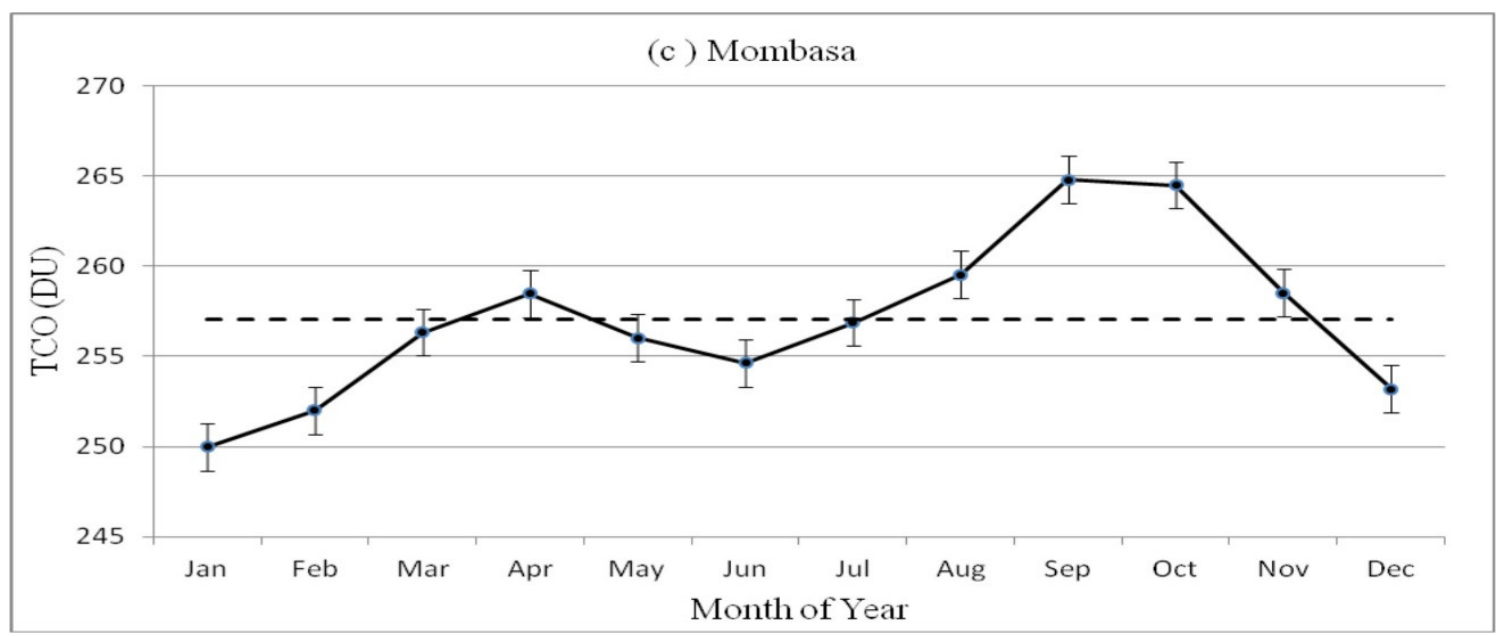

Figure 7(c). Plots of mean seasonal TCO variability measured at Mombasa

Figure 7 (a), (b) and (c) show the mean seasonal variation of TCO observed at the three Kenyan cities with the normalized standard deviations for each month and a dotted horizontal line indicating the average TCO. A mean monthly TCO value of $254.74 \pm 4.80 \mathrm{DU}, 253.92 \pm 4.55 \mathrm{DU}$ and $257.07 \pm 4.51 \mathrm{DU}$ is observed in Nairobi, Kisumu and Mombasa respectively. Maximum and minimum values observed were respectively $260.68 \mathrm{DU}$ and 245.65 DU at Nairobi; 260.25 DU and 245.54 DU at Kisumu; and 264.79 DU and 249.98 DU at Mombasa. These maximum and minimum values of TCO are observed in the months of September and January respectively.

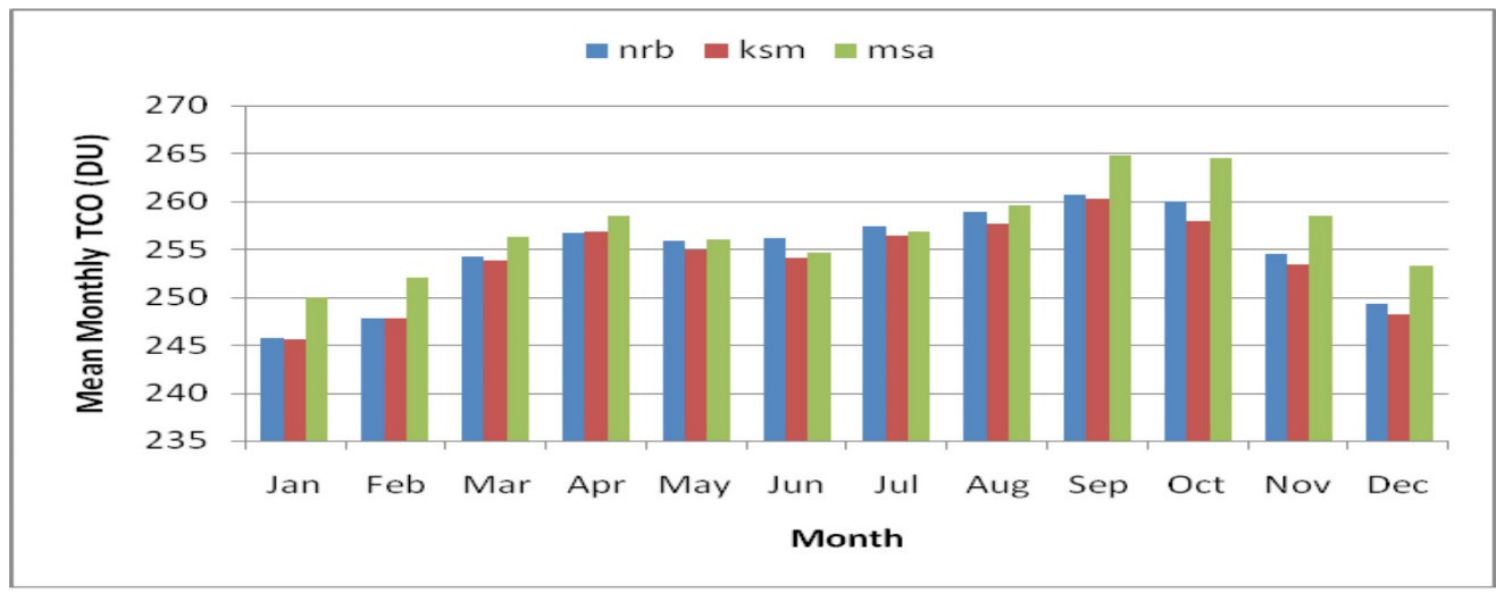

Figure 8. Average of mean monthly TCO values for the three Kenyan cities

The monthly analysis of TCO shows a lot of variations in ozone thickness throughout the year. There are only two months (September and October) at Mombasa and Nairobi during which ozone thickness remains at or far above the permissible limits of ozone of 260 DU near the equator. The rest of the months, for all the cities, the ozone layer becomes thin and the values of ozone calculated below the 260 DU mark (Figure 8).

It can also be noted from Figure 4 and Figure 8 that the values of TCO are functions of latitude. This can be seen from the values of TCO at different cities in each month and year. The higher values throughout the months of the years and the years occurred at Mombasa while the lowest occurred at Kisumu.

\subsection{Seasonal Variation}

The percentage variability of TCO in the three cities was studied for each month of the year as indicated in Figure 9. The seasonal variations of variability are in the range of between $2 \%-4 \%$. The highest percentage TCO variabilty is observed in June at Nairobi (3.91\%) while Kisumu and Mombasa recorded the same value of Maximum (3.70\%) in December and minimum value of $2.87 \%$ in October. All the cities recorded a minimum value in the month of October as displayed in Figure 9. 


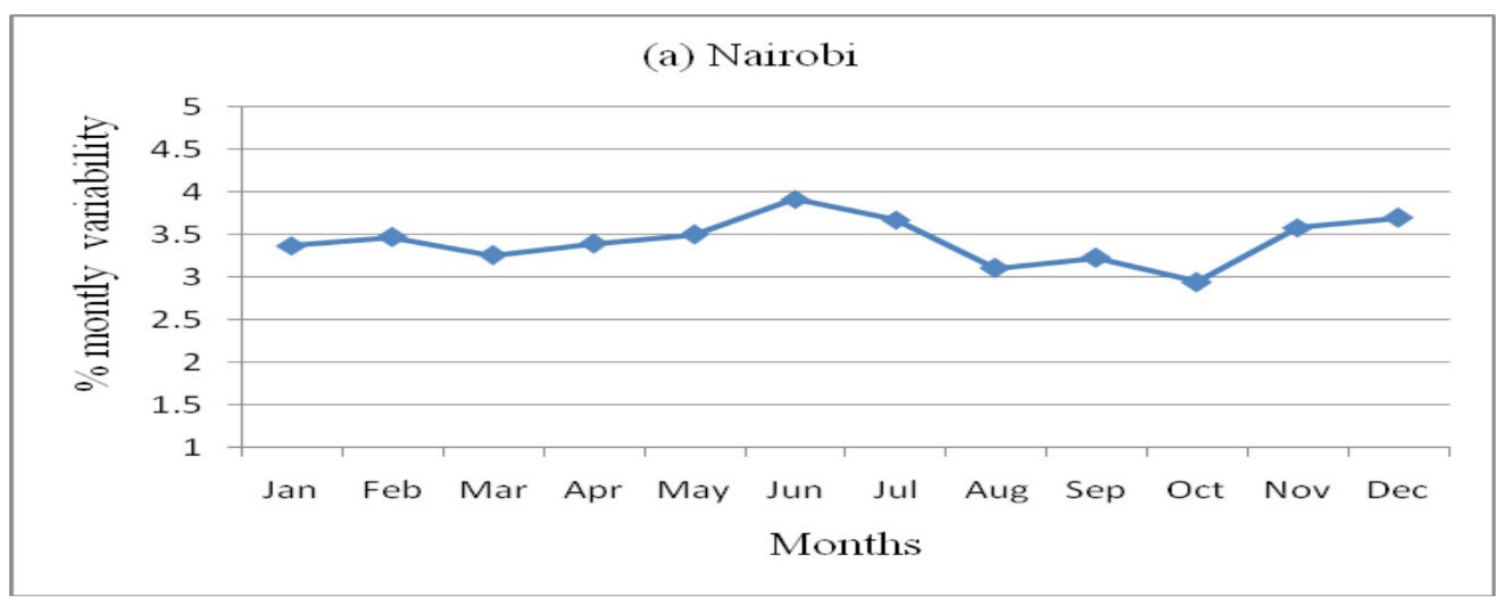

Figure 9(a). Mean seasonal variations of the month to month percentage variability for TCO at Nairobi

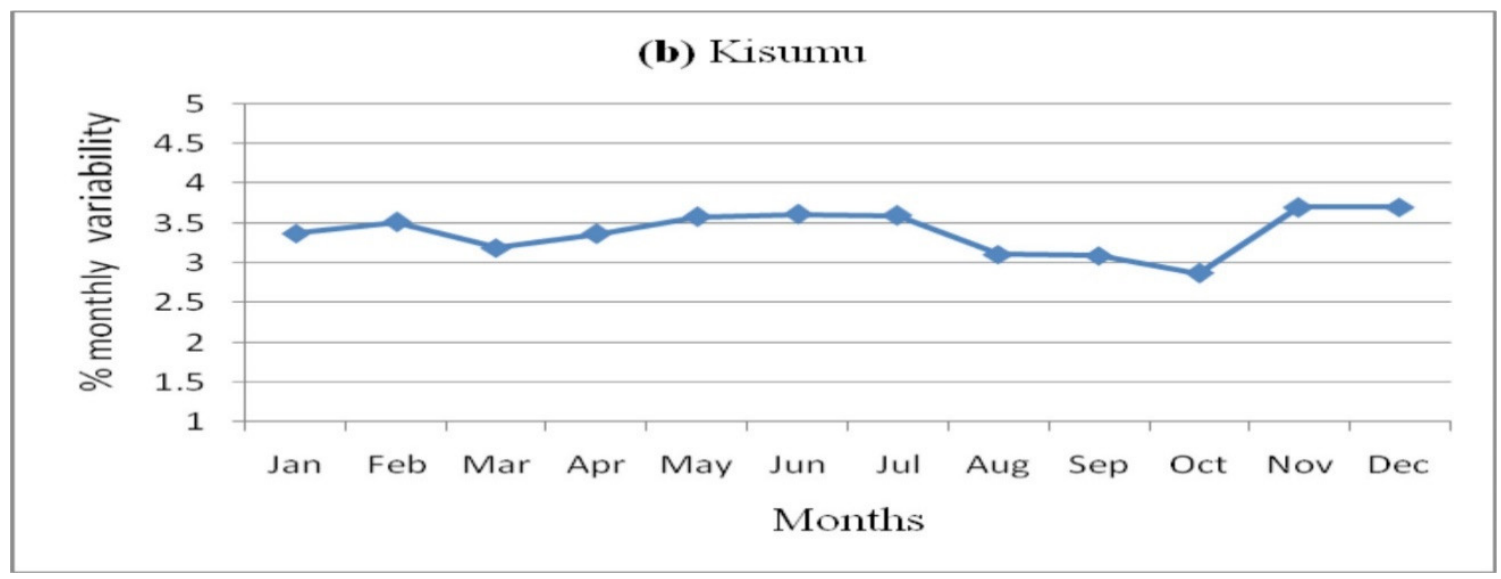

Figure 9(b). Mean seasonal variations of the month to month percentage variability for TCO at Kisumu

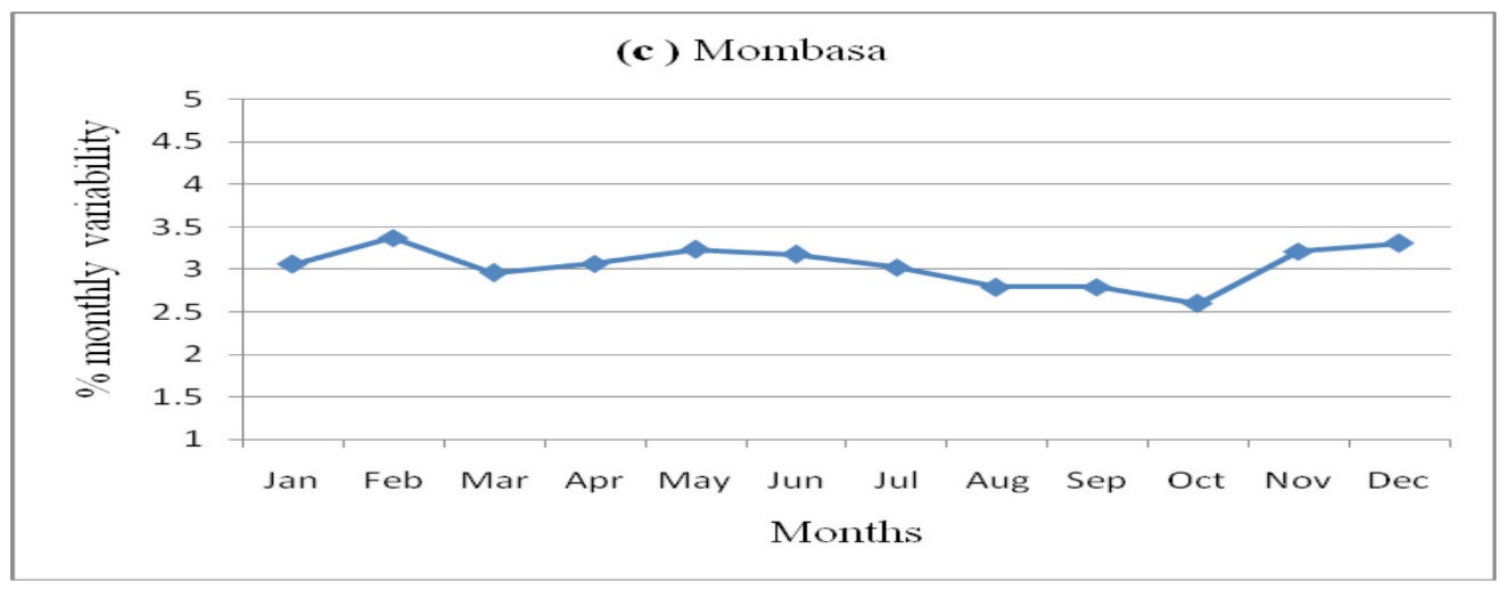

Figure 9(c). Mean seasonal variations of the month to month percentage variability for TCO at Mombasa

Kenya has four seasons; long rains season from March - May, dry-cold season from June - August, a short rain season from September to November and lastly a dry hot season from December to February. 


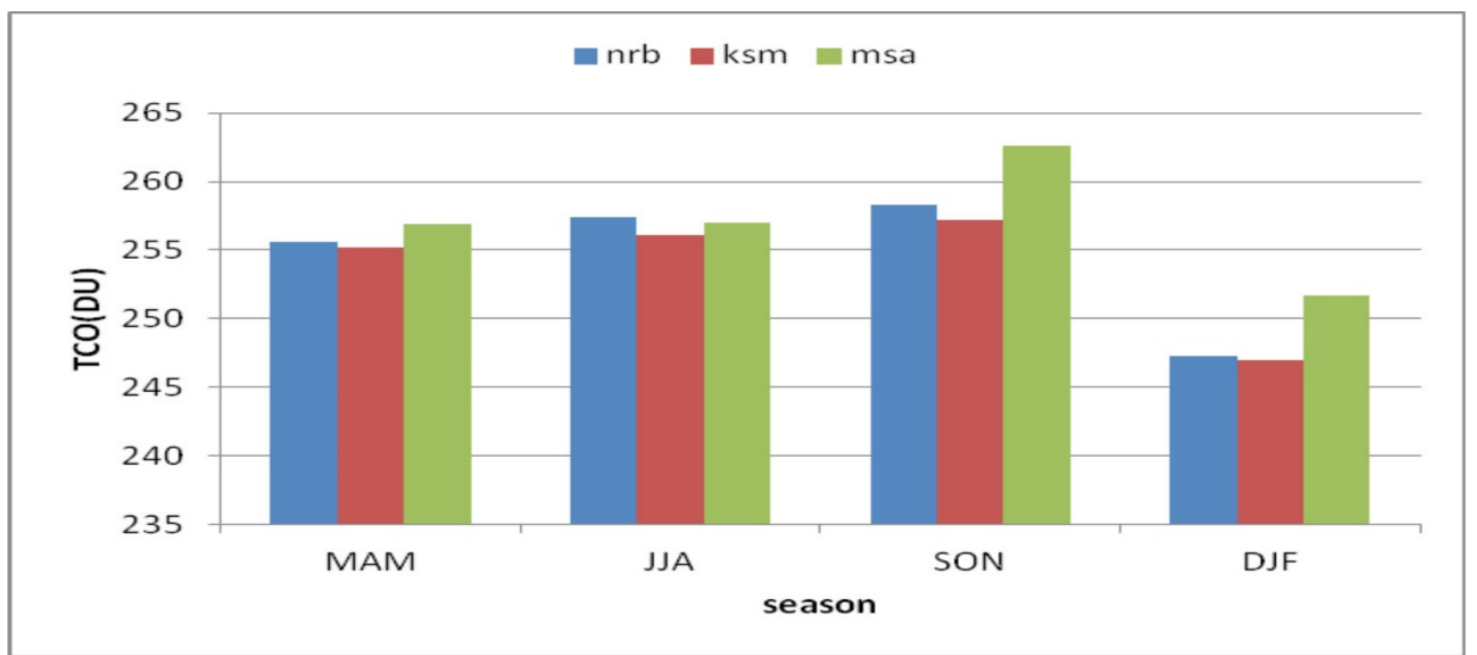

Figure 10. The average of the seasonal values for the three cities; Nairobi (nrb), Kisumu (ksm) and Mombasa (msa)

It is clear that as the maximum values of TCO at each city appear at the months of ASO season followed by the months of MAM seasons. The minimum values of TCO appear at the months of DJF season. Figure 10 shows the seasonal values of TCO for the three cities. The lowest TCO values at these cities appear in the DJF season while the higher values appear in the SON season. The behavior of ozone varies from season to season. Figure 10 shows that TCO remains above permissible limit of 260 DU in the SON season at Mombasa.

Ayoma, Gilbert and Bertrand (2004) reported total ozone measurements over Nairobi with a Dobson instrument, confirming maximum total ozone content during the short rainy season and a minimum in the warm-dry season. Muthama (1989) showed that minimum total ozone amount occurred around January and February (the warm-dry season) and maximum during September and October (the short rainy season). Shilenje and Ongoma (2014) in their study observed a negative correlation $(r=-0.13)$ between monthly ozone concentration and temperature over Nairobi indicating that the variation of monthly ozone concentration is inversely proportional to temperature in the area of study.

Monthly mean values of TCO show distinct seasonal variation with minimum and maximum values occurring in warm -dry season and short rain season respectively. This shows that various air mass circulation specific to each season are responsible for the variability of TCO therefore ozone concentration will vary depending on the season of the year. Ozone exchange between the stratospheric and tropospheric occurs seasonally (Diab, Thompson, Mari, Ramsay \& Cotzee, 2004). Using the ground based measurements, Diab et al., (2004) were able to show the seasonal variations over Irene in South Africa. Hence, the QBO acts to increase the stratospher - troposphere ozone exchange since it is considered to be the cause of circulation in the upper level atmosphere.

Table 3. Seasonal analysis of the total change in TCO over the Kenyan cities $1985-2011$

\begin{tabular}{lcccccc}
\hline & \multicolumn{7}{c}{ TCO } \\
\cline { 2 - 7 } & Nairobi/yr & Total change & Kisumu/yr & Total change & Mombasa/yr & Total change \\
\hline Dec-Jan-Feb & 0.012 & 0.324 & 0.007 & 0.189 & -0.046 & -1.242 \\
Mar-Apr-May & 0.026 & 0.702 & 0.033 & 0.891 & 0.019 & 0.513 \\
Jun-Jul-Aug & -0.174 & -4.698 & -0.139 & -3.753 & -0.146 & -3.942 \\
Sep-Oct-Nov & -0.223 & -6.021 & -0.237 & -6.399 & -0.191 & -5.157 \\
\hline
\end{tabular}

Table 3 shows the seasonal analysis of the total change in TCO in Nairobi, Kisumu and Mombasa during the study period. The maximum decline change in TCO thickness is found in the SON season for all the cities with Kisumu registering the highest change of - 6.4 DU while Mombasa registered the lowest change of -5.2 DU during this season. The minimum decline change in TCO thickness is found in the DJF season. 


\section{Conclusion}

The annual, monthly and seasonal analysis of TCO has been done during the study period $(1985-2011)$ in the three Kenyan cities namely Nairobi, Kisumu and Mombasa. All the analyses have shown decreasing trend of TCO. The annual depth of TCO is 2.158 DU at Nairobi, 1.759 DU at Kisumu and 2.164 DU at Mombasa. The maximum value of TCO is observed in the SON season while the lowest value of TCO is observed in the DJF season in all the stations. The TCO is observed to be higher at Mombasa during all seasons of the year. Higher TCO values are observed during April and October while small values of TCO are seen between December and March in all the three stations (Figure 6).

The annual TCO percentage variability ranges between $1 \%$ and $6 \%$ with the highest variability observed in the year 2010 at Mombasa (5.76\%) while the lowest is observed in 2005 at Kisumu. The seasonal variation of variability ranges between $2 \%$ and $4 \%$, highest of $3.91 \%$ in June (Nairobi) and lowest variability in the month of October in all the cities, hence the yearly variations of percentage TCO variability show more fluctuations than the seasonal ones. Overall, January 1988 registered the minimum value of TCO in all the three cities while July 1990 registered the maximum value in both Nairobi and Kisumu.

\section{Recommendation}

The general TCO characteristics at the three cities should be compared by using the monthly mean concentration of daily maximum, average and daily minimum for each month. More Kenyan towns, both from the north and south of the equator need to be analyzed for variability and trend using satellite instruments even when there are no ground based instruments in the respective towns, since TCO is a function of latitude.

\section{Acknowledgements}

We would like to thank Greg Bodeker and Jan Markus Diezel for providing the combined total column ozone database for the three Kenyan cities. We are also grateful to the National Commission for Science, Technology and Innovation (NACOSTI) - the research authorizing body in Kenya, for provision of funds that enabled us to undertake this research.

\section{References}

Akinyemi, M. L. (2007). The influence of some atmospheric phenomena on total ozone concentration over the tropics. Australian Journal of Basic and Applied Sciences, 1(4), 497-505.

Andrews, D. G. (2000). An introduction to atmospheric Physics. Cambridge, UK: Cambridge University Press. http://dx.doi.org/10.1017/CBO9780511800771

Ayoma W., Gilbert, L., \& Bertrand, C. (2004). Variability in the observed vertical distribution of ozone over equatorial Eastern Africa: An analysis of Nairobi ozonesonde data 2004. Proceedings of the Quadrennial Ozone Symposium, 1-8 June, Kos, Greece.

Bais, A. F., \& Lubin, D. (2007). Surface Ultraviolet Radiation: Past, Present, and Future. In Scientific Assessment of Ozone Depletion: 2006, Chapter 7, WMO Global Ozone Research and Monitoring Project-Report No. $50,7.1-7.54$.

Baldwin, M. P., Gray, L. J., Dunkerton, T. J., Hamilton, K., Haynes, P. H., Randel, W. J., ... Takahashi, M. (2001). The quasi biennial oscillation. Reviews of Geophysics, 39, 179-229. http://dx.doi.org/10.1029/1999RG000073

Bodeker, G. E., Hassler, B., Young, P. J., \& Portmann, R. W. (2013). A vertically resolved, global, gap-free ozone database for assessing or constraining global climate model simulations. Earth System Science Data, 5, 3143. http://dx.doi.org/10.5194/essd-5-31-2013

Bodeker, G. E., Nitzbon, J., \& Tradowsky J. ('in preparation'). A global total column ozone climate data record. Manuscript prepared for Mech. Sci. Discuss. Date: 15 October 2014

Brasseur, G., \& Solomon, S. (2005). Aeronomy of the middle atmosphere (3rd ed.). Springer, Dordrecht, Netherlands.

Chapman, S. (1930). A theory of upper atmospheric ozone. Mem. Roy. Meteorol. Soc., 3, 103-125.

Dessler, A. E. (2000). The chemistry and physics of stratospheric ozone. San Diego, California: Academic Press.

Diab, R. D., Thompson. A. M., Mari, K., Ramsay, L., \& Coetzee, G. J. R. (2004). Tropospheric ozone climatology over Irene, South Africa, from 1990 to 1994 and 1998 to 2002. Journal of Geophysical Research: Atmospheres (1984-2012), 109 (D20). 
Garny, H., Grewe, V., Dameris, M., Bodeker, G. E., \& Stenke, A. (2011). Attribution of ozone changes to dynamical and chemical processes in CCMs and CTMs. Geoscientific Model Development, 4, 271-286. http://dx.doi.org/10.5194/gmd-4-271-2011

GCOS - 138. (2010). Implementation plan for the global observing system for climate in support of the UNFCCC, GOOS-184, GTOS-76, WMO-TD/No. 1523. Geneva: World Meteorological Organization.

Gray, L. J. (2010). In: Stratospheric equatorial dynamics. American Geophysical Union, Washington D.C.190:67. http://dx.doi.org/10.1029/2009gm000868

Gray, L. J., Rumbold, S. T., \& Shine, K. P. (2009). Stratospheric temperature and radiative forcing response to 11 - year solar cycle changes in irradiance and ozone. Journal of the Atmospheric Sciences, 66, 2402-2417. http://dx.doi.org/10.1175/2009JAS2866.1

Haigh, J. D. (1994). The role of stratospheric ozone in modulating the solar radiative forcing of climate. Nature, 370, 544 -546. http://dx.doi.org/10.1038/370544a0

Haynes, P. H. (2005). Stratospheric dynamics. Annual Review of Fluid Mechanics, 37, 263-293. http://dx.doi.org/ 10.1146/annurev.fluid.37.061903.175710

Holton, J. R. (2004). An Introduction to dynamic meteorology (4th ed.). Elsevier Academic Press, San Diego, California, USA.

Holton, J. R., Haynes, P. H., McIntyre, M. E., Douglass, A. R., Rood, R. B., \& Pfister, L. (1995). Stratosphere troposphere exchange. Reviews of Geophysics, 33. http://dx.doi.org/10.1029/95RG02097

Hood, L. L., \& Soukharev, B. E. (2003). Quasi - decadal variability of the tropical lower stratosphere: The role of extra tropical wave forcing. Journal of the Atmospheric Sciences, 60, 2389-2403. http://dx.doi.org/10.1175/ 1520-0469(2003)060<2389:QVOTTL $>2.0 . C O ; 2$

KNBS. (2010). The 2009 Kenya population and housing census. Nairobi: KNBS.

Muthama, N. J. (1989). Total atmospheric ozone characteristics over a tropical region. MSc thesis. Department of Meteorology, University of Nairobi, Kenya.

Obiekezie, T. N. (2009). Sunshine activity and total column ozone variation in Lagos, Nigeria. Moldavian Journal of the Physical Sciences, 8(2), 169-172.

Ongoma, V., Muthama, N. J., \& Gitau, W. (2013). Evaluation of urbanization influences on urban winds of Kenyan cities. Ethiopian Journal of Environmental Studies and Management, 6, 223-231. http://dx.doi.org/10.4314/ ejesm.v6i3.1

Oyekola, O. S. (2011). Climatology of equatorial stratospheric ozone and trends over Lagos (6.6 N, 3.3 E). Ozone: Science and Engineering: The Journal of the International Ozone Association, 33(6), 489-500. http://dx.doi.org/10.1080/01919512.2011.615058

Plumb, R. A. (2002). Stratospheric transport. Journal of the Meteorological Society of Japan, 80, 793-809. http://dx.doi.org/10.2151/jmsj. 80.793

Randall, C. E., Harvey, V. L., Singleton, C. S., Bailey, S. M., Bernath, P. F., Codrescu M., Nakajima H., \& Russel III, J. M. (2007). Energetic particle precipitation effects on the Southern Hemisphere stratosphere in 19922005. Journal of Geophysics Research. 112, D08308. http://dx.doi.org/10.1029/2006JD007696

Reid, G. C. (1994). Seasonal and interannual temperature variations in the tropical stratosphere. J. Geophys. Res., 99, 18923-18932. http://dx.doi.org/10.1029/94jd01830

Rind, D., Shindell, D., Perlwitz, J., Lerner J., Lonergan, P., Lean, J., \& McLinden, C. (2004). The relative importance of solar and anthropogenic forcing of climate change between the Maunder Minimum and the present. Journal of Climate, 17, 906-929. http://dx.doi.org/10.1175/1520-0442(2004)017<0906:TRIOSA>2.0.CO;2

Shilenje, Z. W., \& Ongoma, V. (2014). Observed surface ozone trend in the year 2012 over Nairobi, Kenya. Atmósfera, 27(4), 377-384.

Shindell, D. T., Faluvegi, G., Miller, R. L., Schmidt, G. A., Hansen, J. E., \& Sun, S. (2006). Solar and anthropogenic forcing of tropical hydrology, Geophysical. Research. Letters, 33. L24706 http://dx.doi.org/10. 1029/2006GL027468

Stanford, J. L., Ziemke, J. R., McPeters, R. D., Krueger, A. J., \& Bhartia, P. K. (1995). Spectral analyses, climatology and interannual variability of nimbus-7 TOMS version 6 total column ozone. Bulletin of the 
American Meteorological Society. NASA Reference Publication 1360, NASA Scientific and Technical Information Branch.

Thiong'o, K. K. (2014). Kenya Meteorological Service National report of the 9th Meeting of the Ozone Research Managers of the Parties to the Vienna Convention Geneva, Switzerland.

Whitten, R. C., \& Prasad, S. S. (1985). Ozone in free atmosphere. New York: Van Nostrand Reinhold Company.

Zahid, M., \& Rasul, G. (2010). Status of stratospheric ozone over Pakistan 1987-2008. Journal of Environmental Protection, 4(12), 374-383. http://dx.doi.org/10.4236/jep.2010.14043

\section{Copyrights}

Copyright for this article is retained by the author(s), with first publication rights granted to the journal.

This is an open-access article distributed under the terms and conditions of the Creative Commons Attribution license (http://creativecommons.org/licenses/by/3.0/). 